\title{
A periferia do Centro: produção artística da população invisibilizada do Centro do Rio de Janeiro
}

\author{
The Periphery of the Centre: Artistic production of \\ the invisiblized population of Rio de Janeiro's
}

Centre

\section{La periferia del Centro: producción artística de la población invisibilizada del Centro de Río de Janeiro}

Clarisse Monteiro *

http://dx.doi.org/10.22409/poiesis.1931.117-134

\begin{abstract}
RESUMO: Constituída na dinâmica das interações com e entre pessoas e em diferentes tempos, as cidades não podem ser pensadas como uma entidade apartada de seus moradores. Da mesma forma, é necessário pensar a arte levando em consideração os atores sociais envolvidos em sua produção e fruição. É por essa perspectiva que o presente artigo busca lançar luz sobre o Centro da cidade do Rio de Janeiro e suas características, colocando em pauta uma discussão sobre as noções de centro e periferia consolidadas por um histórico brasileiro de exclusão social, cultural e urbanística. Para isso, apresentaremos algumas produções artísticas de classes populares da região junto ao projeto social Pequenas Vozes do Carmelo.
\end{abstract}

PALAVRAS-CHAVE: centro; periferia; arte; políticas culturais; exclusão

\footnotetext{
"Clarisse Monteiro é atriz, arte educadora e mestranda em Estudos Contemporâneos das Artes (linha de pesquisa Estudo das Artes em Contextos Sociais) na UFF. Bolsista CAPES. E-mail: clarissemontteiro@gmail.com
} 
ABSTRACT: Constituted among the dynamics of the interactions with and between different people through different times, cities must not be thought as separate entities from their inhabitants. Likewise, when thinking about art it is imperative to take into consideration the social actors involved in its production and fruition. It is through this perspective that the present article sheds light on Rio de Janeiro's City Centre and its characteristics, bringing up the discussions concerning the concepts of centre and periphery consolidated by a brazilian history of social, cultural and urbanistic exclusion. In order to achieve that, a few artistic processes and products made by local low-income classes in the social project Pequenas Vozes do Carmelo are presented.

KEYWORDS: centre; periphery; art; cultural policies; exclusion

RESUMEN: Constituida en la dinámica de las interacciones con y entre personas y en diferentes tiempos, las ciudades no pueden ser pensadas como una entidad apartada de sus habitantes. De la misma forma, es necesario pensar el arte considerando los actores sociales envueltos en su producción y fruición. Es bajo esa perspectiva que el presente artículo busca lanzar luz sobre el Centro de la ciudad de Río de Janeiro y sus características, poniendo en pauta una discusión sobre las nociones de centro y periferia consolidadas por un historial brasileño de exclusión social, cultural y urbanística. Para ello, presenta algunas producciones artísticas de clases populares de la región junto al proyecto social Pequenas Vozes do Carmelo.

PALABRAS CLAVE: centro; periferia; arte; políticas culturales; exclusión

Como citar: MONTEIRO, Clarisse. A periferia do Centro: produção artística da população invisibilizada do Centro do Rio de Janeiro. Poiésis, Niterói, v. 19, n. 31, p. 117-134, jan./jun. 2018.

doi: http://dx.doi.org/10.22409/poiesis.1931.117-134

Poiésis, Niterói, v. 19, n. 31, jan./jun. 2018. 


\section{A periferia do Centro: produção artística da população invisibilizada do Centro do Rio de Janeiro}

Várias são as cidades dentro da cidade e cada uma carrega consigo uma infinidade de complexas características. Conformadas pela dinâmica das interações com e entre pessoas e em diferentes tempos, quanto mais se lança luz sobre elas, mais é possível identificar suas particularidades. É por essa perspectiva que o presente artigo ${ }^{1}$ se desenvolve, observando com olhar atento e reflexivo o Centro da cidade do Rio de Janeiro e a produção artística de classes populares da região, tendo como foco um histórico de exclusão social tanto no que diz respeito ao planejamento urbano quanto às políticas culturais.

O Brasil tem como marca profunda de sua história a exclusão, enraizada no processo de colonização do país, fundado no patrimonialismo e nas relações de favor. (MARICATO, 2000) A exclusão urbanística, por exemplo, pode ser observada, dentre outros fatores, pela enorme ocupação ilegal do solo urbano, parte instrínseca desse processo. Não que o país não tenha contado com planos de urbanização nem com legislação específica, elaborados sobretudo durante o século XX. Pelo contrário. Mas há um descompasso entre as ideias que alimentaram esses planos e a produção do espaço urbano real.

Poiésis, Niterói, v. 19, n. 31, jan./jun. 2018. 
As cidades brasileiras têm refletido a lógica da aplicação discriminatória da lei, instrumento fundamental para o exercício arbitrário do poder em favor de "um mercado imobiliário excludente que, entre outras coisas, vende o cenário como signo de distinção". (MARICATO, 2000, p. 159) Segundo Maricato (2000), a ocupação ilegal da terra urbana é parte do modelo de desenvolvimento urbano no Brasil na medida em que é funcional para as relaç̃oes políticas arcaicas, para a manutenção do baixo custo de reprodução da força de trabalho, como também para um mercado imobiliário restrito e especulativo que se sustenta ainda sobre a estrutura fundiária.

Funcional para essa estrutura de mercado, tal prática é, entretanto, disfuncional para as relações democráticas, igualitárias e para a ampliação da cidadania, já que interfere de forma radical na qualidade de vida urbana e determina quem terá ou não, efetivamente, o direito à cidade. Deste cenário de escassez de moradias e de segregação territorial surgem as periferias urbanas e suas manifestações culturais, alvos de reflexões acadêmicas em diversas áreas.

Vários são os estudos sobre as manifestações artístico-culturais das periferias, como o movimento hip hop e suas expressões tal qual o rap e o funk (na música), o break e o passinho (na dança) e o grafite (nas artes visuais) ${ }^{2}$. É comum encontrarmos, de um modo geral, as periferias identificadas como as regiões geograficamente à margem da cidade, como, no caso do Rio de Janeiro, os subúrbios cariocas (Zonas Norte e Oeste) e favelas. O Centro do Rio, entretanto, não representa apenas área ocupada pela elite carioca. Sua estrutura de habitação é mais complexa do que isso e também está condicionada pela lógica do mercado imobiliário, fazendo conviver centro e periferia em um mesmo espaço e tempo.

O Centro é um bairro predominantemente comercial e turístico e abriga a maior comcentração de equipamentos culturais da cidade, liderando a lista de bairros cariocas com mais opções de cultura ${ }^{3}$. Além disso, é um lugar de fácil acesso, com ampla malha de transportes. Ao mesmo tempo, parte de seu território também é residencial, caracteriza-

Poiésis, Niterói, v. 19, n. 31, jan./jun. 2018. 
do por diversificados tipos de moradia, dentre elas as de baixo aluguel ou ocupações ilegais, habitadas por pessoas em situação de vulnerabilidade social ${ }^{4}$. Estas, cercadas por um universo de desprovimento, boa parte com baixa escolarização, composta por grande número de imigrantes, muitas vezes sequer conhecem a existência desses equipamentos. (Fig. 1)

Embora na região sejam oferecidas variadas opções de cultura, muitas delas a preços baixos ou gratuitos, e embora a visitação a esses espaços tenha aumentado expressivamente nas últimas décadas ${ }^{5}$, os moradores de baixa renda da localidade não os frequentam, ainda que sejam muitos os programas de arte-educação que se dedicam a desenvolver projetos de mediação.

Vários são os motivos para essa não visitação. Segundo Howard Becker (1977, p. 213), "a possibilidade de experiência artística surge da existência de um corpo de convenções a que os artistas e a plateia podem referir-se ao compreender o trabalho", referindo-se a uma plateia que domina/participa do mesmo corpo de convenções no qual o objeto de arte foi idealizado e produzido. Se a população em questão não faz parte do conjunto de pessoas que partilha desse corpo de convenções é natural que a arte ali apresentada não seja de seu interesse.

Já segundo a crítica social do julgamento de gosto, proposta por Bourdieu em A Distinção (1979), a vinculação de uma hierarquia do gosto a uma hierarquia social nos mostra que, embora esses equipamentos culturais estejam localizados no Centro da cidade, eles fazem parte e refletem um estilo de vida que não é o da população que mora ali, atendendo muito mais à classe que possui o princípio/disposição de estetização, ou seja, àquela que está no topo da hierarquia social. Desta forma, fica evidente que os obstáculos à visitação são, antes de tudo, simbólicos (socialização, habitus cultuado) e não materiais (distância espacial, barreira tarifária). (BOURDIEU; DARBEL, 1969)

Nesse cenário em que convivem um centro e uma periferia no mesmo espaço urbano, é possível perceber a complexidade da região, com a coexistência de múltiplas culturas e 


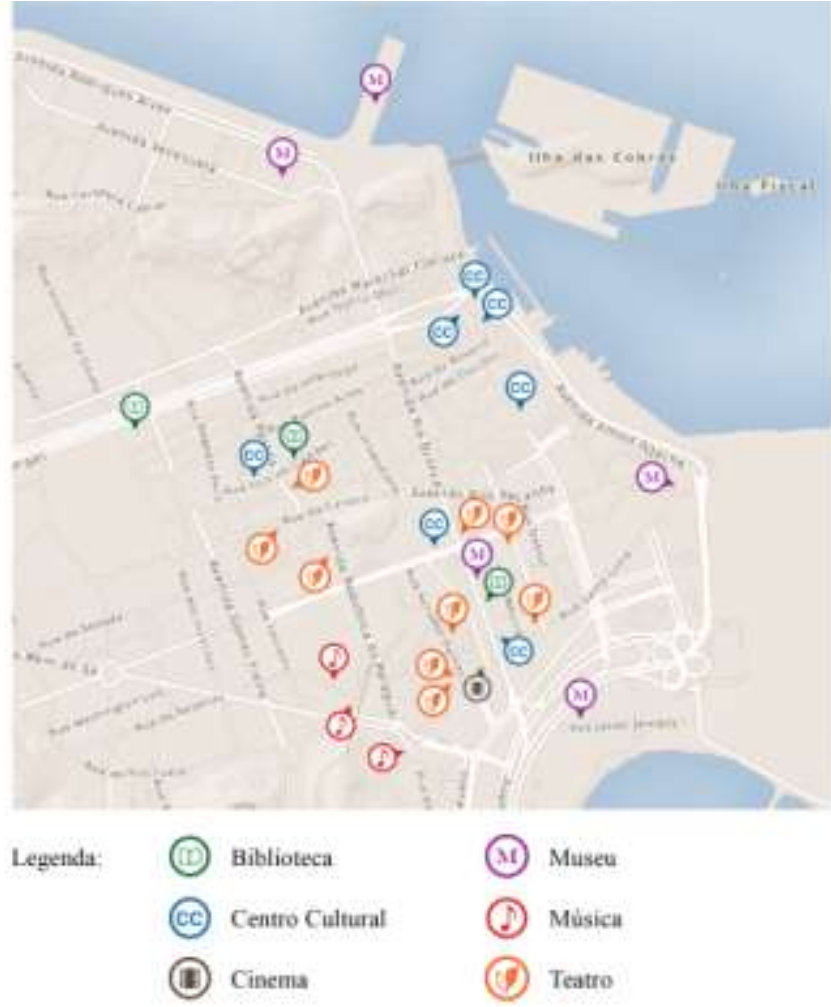

Fig. 1 - Mapa Cultural do Centro do Rio de Janeiro, 2018.

(Fonte: acervo pessoal)

Poiésis, Niterói, v. 19, n. 31, jan./jun. 2018. 
formas simbólicas. Pensar o Centro do Rio como lugar representativo de uma cultura apenas - a cultura de elite presente nos principais equipamentos culturais - é reforçar uma exclusão praticada por séculos e presente também no desenvolvimento de políticas culturais no país.

\section{Tão perto e tão distante: o lugar das periferias na história das políticas culturais brasileiras}

Marcada por forte viés elitista e autoritário, a história das políticas culturais brasileiras, segundo Rubim (2007, p. 11), pode ser condensada em expressões como autoritarismo, caráter tardio, descontinuidade, desatenção, paradoxos, impasses e desafios. Sua inauguração somente pode ser pensada a partir de 1930, período de grandes alterações políticas, econômicas e culturais. A partir desse momento, observa-se um processo cíclico de fazimento e desfazimento das tentativas de construção das políticas públicas de cultura, acompanhando tanto as ideologias de governo quanto de figuras emblemáticas à frente de secretarias e ministérios. Sendo assim, os discursos e práticas oscilam entre propostas conservadoras e autoritárias vinculadas a qualquer governo ditatorial, propostas neoliberais que jogam nas mãos do mercado a direção do fazer cultural, momentos de vazio e tentativas desafiadoras de lidar com essas heranças históricas.

Alguns pontos expressivos dessa história são relevantes para pensarmos as noções de centro e de periferia sobre as quais trata este artigo. A começar pela atuação de Mário de Andrade quando passou pelo Departamento de Cultura da Prefeitura da cidade de São Paulo (1935-1938). Segundo Rubim (2007, p. 15):

Mário de Andrade inova em: 1. estabelecer uma intervenção estatal sistemática abrangendo diferentes áreas da cultura; 2. pensar a cultura como algo "tão vital como o pão"; 3. propor uma definição ampla de cultura que extrapola as belas artes, sem desconsiderá-las, e que abarca, dentre outras, as culturas populares; 4. assumir o patrimônio não só como material, tangível e possuído pelas elites, mas também como algo imaterial, intangível e pertinente aos diferentes estratos da sociedade; 5. patrocinar duas missões etnográficas às regiões amazônica e nordestina para pesquisar suas populações, deslocadas do 
eixo dinâmico do país e da sua jurisdição administrativa, mas possuidoras de significativos acervos culturais (modos de vida e de produção, valores sociais, histórias, religiões, lendas, mitos, narrativas, literaturas, músicas, danças etc.).

Mário de Andrade causa impacto revolucionário com seus experimentos, ultrapassando as fronteiras da cidade e ganhando dimensão nacional. Imbuído da visão do nacional-popular que representa a nação de forma unificada, o patrocínio de duas missões etnográficas ao norte e nordeste do país para pesquisar suas populações revela que a busca pela identificação e (re)conhecimento do outro envolve também uma longa distância geográfica. 0 outro é todo aquele que não é/está na cidade/no centro, no eixo dinâmico do país, desconsiderando, em certa medida, a diversidade do meio urbano. Atitude que gira em torno de uma ideia de cidade enquanto sinônimo de cultura dominante, de elite.

O segundo ponto expressivo diz respeito às leis de incentivo fiscal às quais ficaram restritas as políticas públicas de cultura desde o governo de José Sarney (1985-1989) até o de Fernando Henrique Cardoso (1995-2002), quando o projeto neoliberal é implementado de maneira mais enfática no Brasil (RUBIM, 2007). Em 1986, no governo Sarney, cria-se a Lei Sarney (Lei 7.505/86), a primeira lei brasileira de incentivos fiscais para financiar a cultura. No governo de Fernando Collor de Melo (1990-1992), a Lei Sarney é extinta, dando origem à outra lei de incentivo, a Lei Rouanet (Lei 8.313/91), legislação vigente até hoje com algumas alterações. A cultura passa a ser mercadoria e, assim, não é de surpreender que a publicação mais famosa do Ministério da Cultura no governo FHC tenha sido a Cultura é um bom negócio (Ministério da Cultura, 1995).

Essa lógica das leis de incentivo - que privilegia o mercado, ainda que utilizando quase sempre dinheiro público - torna-se componente fundamental do financiamento à cultura no Brasil, expandindo-se para estados e municípios e para outras leis nacionais. As leis de incentivo passam, então, a serem confundidas com políticas culturais.

A lógica de mercado que opera nesse sistema vem acompanhada de uma série de problemas e críticas, como a exigência crescente de profissionalização - que exclui os cria-

Poiésis, Niterói, v. 19, n. 31, jan./jun. 2018. 
dores que não possuem um nível mínimo de assessoria - , financiamento sobretudo de projetos com visibilidade midiática, favorecimento de linguagens artísticas tradicionais e direcionamento estético. Como bem resume Barbalho (2007, p. 49):

0 resultado é que os criadores passam cada vez mais a ter que adequar suas criações à lógica mercantil. Antes de tudo, ensinam os manuais de marketing cultural, faz-se necessário conhecer o público consumidor, as empresas voltadas para esse público, o interesse da mídia pelo projeto, fazer pesquisas quantitativas e qualitativas... Na competição cada vez mais acirrada entre os criadores pelo patrocínio privado, obtém sucesso aqueles que se identificam ou estão submetidos ao pensamento e ao gosto dominantes.

Assim, como ocorre com os planejamentos urbanísticos nacionais que atuam em favor do mercado imobiliário restrito e especulativo, as políticas culturais resumidas às leis de incentivo revelam-se, portanto, extremamente excludentes.

Por fim, o terceiro momento da história das políticas culturais brasileiras, relevante para este trabalho, se dá no governo Lula (2003-2011), com a atuação de Gilberto Gil. Este, no cargo de Ministro da Cultura (2003-2008), encontra o desafio de administrar as heranças deixadas por décadas de relações de autoritarismo, fragilidade institucional, lógica das leis de incentivo, concentração dos recursos utilizados etc.

Gil persegue a democratização do acesso e da produção cultural, em uma gestão participativa e descentralizadora, abordando a pluralização da questão identitária e reivindicando um "conceito de cultura mais alargado, dito 'antropológico'". (RUBIM, 2007, p. 29) A retomada do papel ativo do Estado nas políticas culturais acontece, entretanto, de maneira oposta à forma autoritária característica das ditaduras de períodos anteriores. Como explica Barbalho (2007, p. 52):

A diversidade não se torna uma síntese, como no recurso à mestiçagem durante a era Vargas e na lógica integradora dos governos militares, nem se reduz à diversidade de ofertas em um mercado cultural globalizado. A preocupação da gestão Gilberto Gil está em revelar os brasis, trabalhar com as múltiplas manifestações culturais, em suas variadas matrizes étnicas, religiosas, de gênero, regionais etc. 
Um dos programas mais representativos dessa ideologia é o Programa Nacional de Cultura, Educação e Cidadania - Cultura Viva, que se volta para os grupos e redes excluídos do sistema vigente, ou seja, para aqueles que não acessam os direitos básicos da cidadania, inclusive o cultural. Importante instrumento de democratização do acesso e da produção cultural, a principal ação do Programa é o Ponto de Cultura no qual, através de edital de seleção pública, o MinC financia projetos de criação e produção culturais promovidos pela sociedade civil, contribuindo "para dar capilaridade à atuação ministerial". (RUBIM, 2007, p. 32)

A ação do programa foi integrada aos estados e municípios brasileiros, criando a Rede de Pontos de Cultura e, no município do Rio de Janeiro, o primeiro edital foi aberto em 2013. Segundo o relatório elaborado pela equipe responsável pela implementação da Rede Carioca, a ideia de centro e periferia tratadas anteriormente são mais claramente enunciadas:

No Rio de Janeiro, assim como na maioria das metrópoles mundiais, a urgência da democratização assim entendida cruza-se com a exigência de descentralização dos canais de acesso à cultura. Uma vez que se voltaram para a questão cultural tendo por base 0 consumo, as açōes do estado e do mercado cariocas resultaram em uma grave concentração de equipamentos e dispositivos no Centro e na Zona Sul da cidade, onde o capital circula e "retrocircula", pondo em marcha um movimento que à vista mais superficial não parece permitir linha de fuga. À centralidade do poder e do acesso corresponde uma circunscrição geográfica em que a cultura aparece como bem ou serviço disponível de maneira quase exclusiva.

Enquanto isso, na Zona Norte, na Zona Oeste e nas favelas cariocas, cuja população é instada a se deslocar até o núcleo central para acessar a produção ofertada, pulsam processos vivos e heterogêneos que, apesar de concorrerem para a construção do retrato do carioca como um povo diverso culturalmente, não costumam ser reconhecidos pelo circuito cultural institucional, sendo raramente tomados como objeto de políticas públicas e constando de maneira esparsa na programação de centros culturais ou nas listas de patrocínio da iniciativa privada. (LOPES ealli, 2014, p. 4)

Poiésis, Niterói, v. 19, n. 31, jan./jun. 2018. 
Percebe-se, assim, que ao aspecto geográfico das noções de centro e periferia estão vinculadas duas identidades distintas que, grosso modo, se constituem da seguinte maneira: (1) o centro como região detentora do poder econômico e capital cultural, local de produção e circulação de cultura elitizada; (2) a periferia como local distante do centro, ou favelas cariocas, que também é produtora de cultura, mas que não tem acesso aos espaços legitimados e legitimadores da cultura de elite e cujas produções carecem de reconhecimento e incentivo.

Deste modo, é possível observar que, embora tal ação tenha sido fundamental para a democratização do acesso e da produção cultural no país, ela ainda se mostrava insuficiente ao desconsiderar uma diversidade mais ampla e profunda da cidade. As noções de centro e periferia, portanto, extrapolam as fronteiras geográficas e se relacionam mais estreitamente com as realidades sociais e com o acesso aos direitos básicos da cidadania, inclusive o cultural.

Para essa população periférica do Centro, a cidadania cultural acaba sendo foco de atuação de projetos sociais vinculados à Secretaria Municipal de Assistência Social e Direitos Humanos (SMASDH), através do Conselho Municipal de Assistência Social (CMAS), do Centro de Referência de Assistência Social (CRAS) e do Conselho Municipal de Direitos da Criança e do Adolescente (CMDCA). Porque, embora invisibilizadas, essas pessoas também são produtoras de arte e cultura e a produção e o acesso democrático à arte também são fundamentais na busca por uma sociedade mais justa e igualitária. É a partir desse contexto que apresento um panorama da produção artística de pessoas das classes populares do Centro, participantes do projeto social Pequenas Vozes do Carmelo.

\section{A periferia do Centro: produção artística e a interação com a cidade}

O Pequenas Vozes do Carmelo é um projeto social mantido pela Província Carmelitana de Santo Elias (PCSE) $)^{6}$ e oferece atendimento social através de oficinas de artes plásticas, teatro, flauta doce, teclado, percussão, violão e canto coral. Desde 2013 atende anual- 
mente cerca de 90 crianças e adolescentes, entre 6 e 17 anos, moradores da Lapa e emtorno, cuja renda familiar não ultrapassa três salários mínimos ${ }^{7}$. (Fig. 2)

Nas oficinas, os jovens desenvolvem as linguagens artísticas a partir da exploração de um tema escolhido a cada ano, resultando em um espetáculo que é apresentado para os familiares. Os musicais, compostos por aproximadamente oito canções intercaladas por cenas que conduzem uma linha dramatúrgica, possuem cerca de uma hora de duração e reúnem no palco, ao mesmo tempo, todos os alunos do projeto, que tocam, cantam e atuam, utilizando cenários, figurinos e adereços elaborados por eles a partir da temática central.

Desde que esta proposta artística foi instituída no projeto, cinco espetáculos foram montados: João e Maria da Lapa (2013), A gente quer é ser um cidadão (2014), Um Rio costurando histórias (2015), Perdidos no folclore (2016) e Nossas prosas nordestinas (2017). Tais espetáculos tiveram como tema, respectivamente, "O Patrimônio Artístico e Cultural do Rio de Janeiro", "Eu, cidadão?", "História, Teatro e Música a partir de 1950 no Rio de Janeiro", "Folclore brasileiro" e "A cultura nordestina".

Fizeram parte dos repertórios canções dos mais diferentes ritmos e compositores, como Pixinguinha, Guinga, Paulo César Pinheiro, Geraldo Vandré, Gonzaguinha, Heitor VillaLobos, MC Marcinho, Zé Keti, Waldemar Henrique, Capiba, Luiz Gonzaga, entre outros. Peças de Oduvaldo Vianna Filho, Nelson Rodrigues e Maria Clara Machado foram estudadas, assim como lendas do folclore brasileiro e movimentos artísticos e culturais como o Modernismo, a Jovem Guarda e a Tropicália. Aulas e ensaios transformaram-se em universos de amplas pesquisas, apoiadas no estímulo e na autonomia dos alunos para a criação artística através do agenciamento de múltiplos saberes.

Poiésis, Niterói, v. 19, n. 31, jan./jun. 2018. 


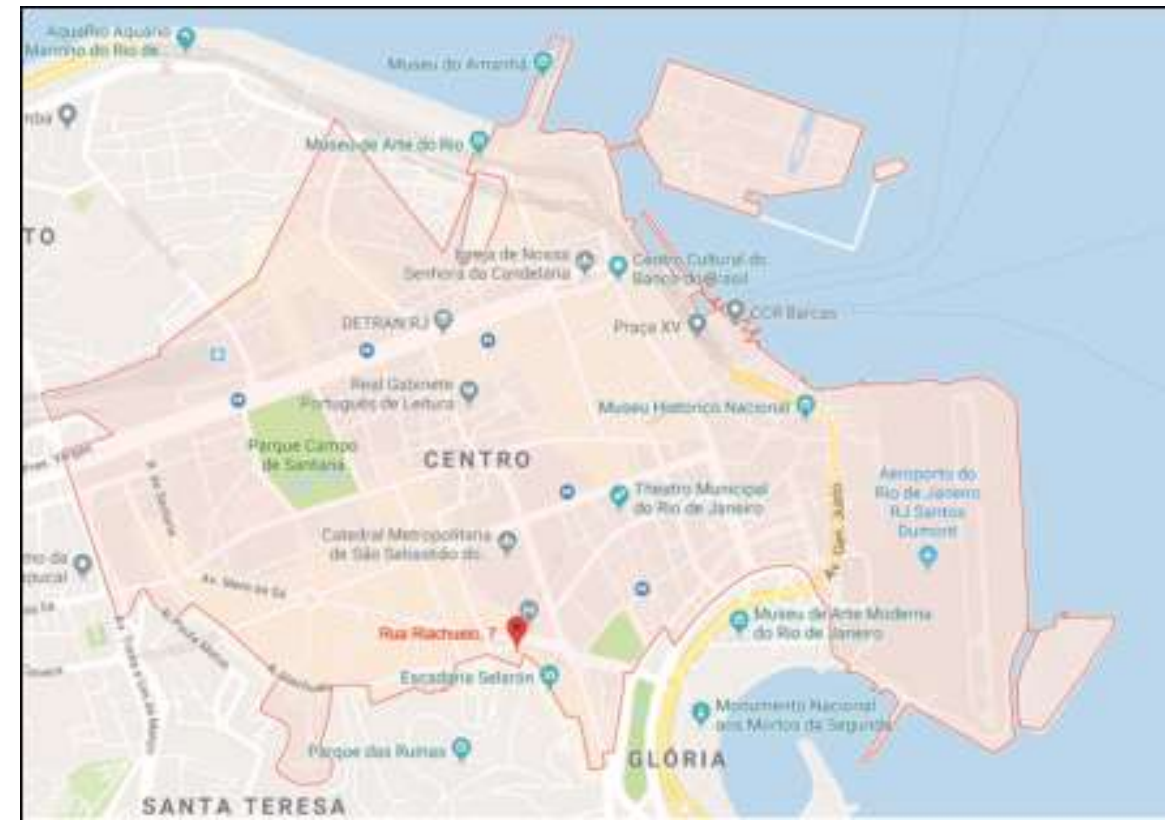

Fig. 2 - Mapa do Centro do Rio de Janeiro / Pequenas Vozes do Carmelo (Lapa). (Fonte: acervo pessoal) 


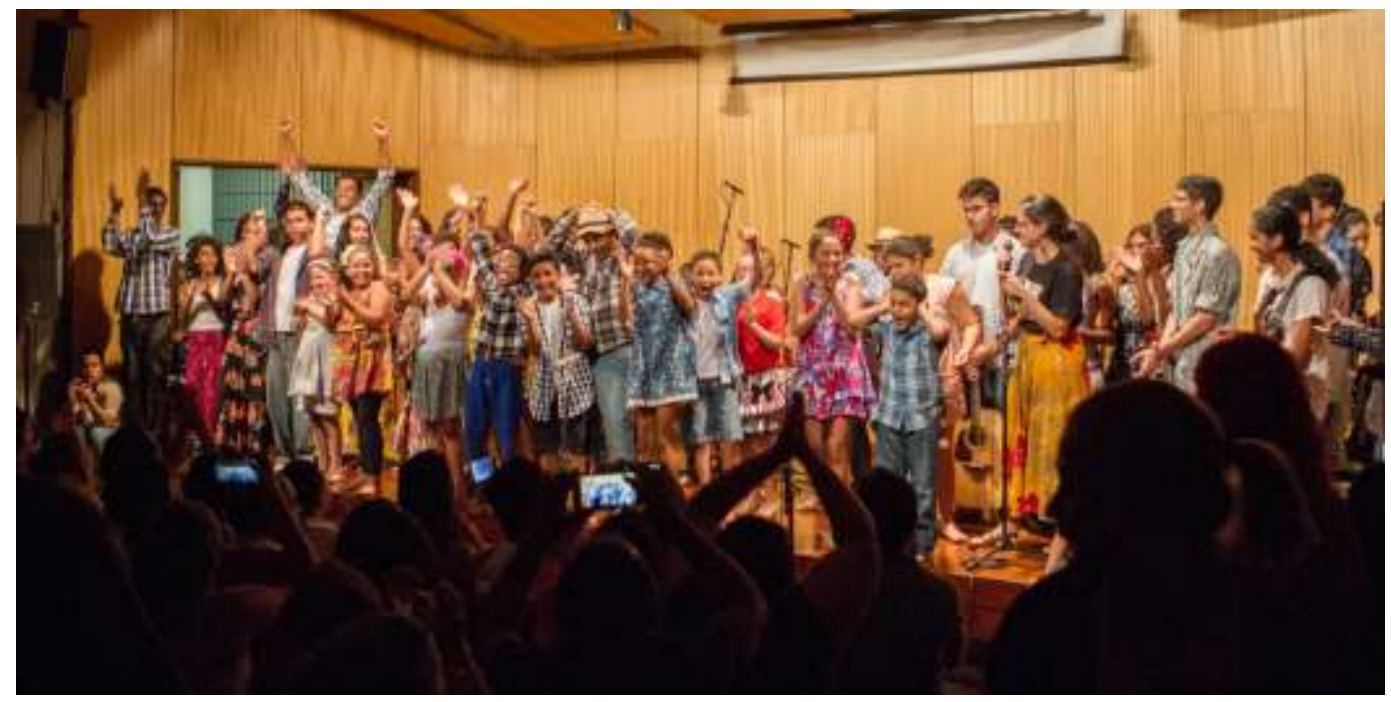

Fig. 3 - Pequenas Vozes do Carmelo, Nossas prosas nordestinas, 2017.

Salão Mário Tavares, Theatro Municipal do Rio de Janeiro

(Fonte: acervo Pequenas Vozes do Carmelo / Foto: Daniel Terra)

Poiésis, Niterói, v. 19, n. 31, jan./jun. 2018. 
Outro fator importante de ser destacado são os locais das apresentações. Há três anos os musicais passaram a ser apresentados em equipamentos culturais do Centro, através de parcerias e concessões feitas pelos gestores dos espaços. Os alunos do Pequenas Vozes do Carmelo já subiram nos palcos da Sala Cecília Meireles/Espaço Guiomar Novaes (2015), Teatro João Caetano (2016) e Salão Mário Tavares/Theatro Municipal (2017). (Fig. 3)

Nesses momentos de apresentação, os jovens permanecem por cerca de cinco horas nas dependências das instituições parceiras, ocupando os palcos, camarins, corredores e plateias, se maquiando, trocando os figurinos, afinando os instrumentos, se aquecendo, comendo e compartilhando as emoções e sentimentos envolvidos nessa preparação. Dessa forma é possível perceber que há uma transformação da relação previamente estabelecida com esses espaços. Se antes esta população não os frequentava devido às barreiras simbólicas existentes, agora as barreiras se diluem a partir de uma apropriação desses lugares. Isso evidencia o fato de que essas barreiras não estão relacionadas exclusivamente aos equipamentos culturais em si, mas a tudo que os conforma, como as artes neles apresentadas, seus habituais frequentadores, funcionários e até mesmo sua localização dentro da própria região da cidade.

Magnani (2002, p. 14-15) nos ajuda a seguir esse raciocínio ao afirmar que não podemos pensar a arte sem levar em consideração os atores sociais, da mesma forma como não podemos pensar a cidade como uma "entidade à parte de seus moradores", já que são "os moradores propriamente ditos que, em suas múltiplas redes, formas de sociabilidade, estilos de vida, deslocamentos, conflitos etc., constituem o elemento que em definitivo dá vida à metrópole". Segundo o autor, isso nos ajuda a evitar a dicotomia que opõe o indivíduo e as megaestruturas urbanas, pois um olhar atento e cuidadoso é capaz de apreender os padrões de comportamento dos mais variados conjuntos de atores sociais na paisagem da cidade no cotidiano: 
Esta estratégia supõe um investimento em ambos os pólos da relação: de um lado, sobre os atores sociais, o grupo e a prática que estão sendo estudados e, de outro, a paisagem em que essa prática se desenvolve, entendida não como mero cenário, mas parte constitutiva do recorte de análise. (MAGNANI, 2002, p. 18)

Pensar a vida da cidade constituída nas dinâmicas das relações com e entre atores sociais torna-se, pois, imperativo na reivindicação de uma sociedade mais igualitária. Tal perspectiva amplia possibilidades de identificação e reflexão sobre aspectos relacionados à herança excludente do país e geralmente desconsiderados por enfoques mais correntes sobre a questão da cidade.

\section{Referências}

BARBALHO, Alexandre. Políticas culturais no Brasil: identidade e diversidade sem diferença. In RUBIM, A. A. C.;BARBALHO, A. (Org.) Políticas culturais no Brasil. Coleção Cult. Salvador: EDUFBA, 2007, p. 37-60.

BECKER, Howard. Arte como ação coletiva. In Uma teoria da ação coletiva. Rio de Janeiro, Ed. Zahar, 1977.

BOURDIEU, Pierre; DARBEL, Alain. O amor pela arte: os museus de arte na Europa e seu público. São Paulo: Zouk, 2003[1969].

BOURDIEU, Pierre. A Distinção: Crítica social do julgamento. Trad. Daniela Kern; Guilherme J. F. Teixeira. Porto Alegre: Editora Zouk, 2015 [1979].

BOURDIEU, Pierre. Gostos de classe e estilos de vida In: ORTIZ, R. (Org.) Pierre Bourdieu: Sociologia. São Paulo: Editora Ática, 1983, p. 82-121.

FREDERICO, Celso. Da periferia ao centro: cultura e política em tempos pós-modernos. Estudos Avançados: Revista do Instituto de Estudos Avançados da Universidade de São Paulo, v. 27, n. 79, p. 239-256, 2013. Disponível em www.revistas.usp.br/eav/article/ view/68714. Acesso em 24/5/2018.

IBRAM PORTAL DO INSTITUTO BRASILEIRO DE MUSEUS. Disponível em http://www. museus.gov.br. Acesso em 4/5/2018.

Poiésis, Niterói, v. 19, n. 31, jan./jun. 2018. 
LOPES, Guilherme et alli. A implementação da rede carioca de pontos de cultura: um movimento de descentralização e de reconhecimento do território. $V$ Seminário Internacional Políticas Culturais - Setor de Políticas Culturais. Rio de Janeiro: Fundação Casa de Rui Barbosa, 2014. Disponível em http://culturadigital.br/politicaculturalcasade ruibarbosa/files/2014/06/Guilherme-Lopes-et-alli.pdf. Acesso em 12/6/2018.

MAGNANI, José Guilherme Cantor. De perto e de dentro: notas para uma etnografia urbana. In: Revista Brasileira de Ciências Sociais, v. 17, n. 49, p. 11-29, jun. 2002.

MAGNANI, José Guilherme Cantor. Festa no Pedaço: cultura popular e lazer na cidade. São Paulo: Hucitec, 1998. [1 ed., Brasiliense, 1984]

MARICATO, Ermínia. As idéias fora o lugar e o lugar fora das idéias: planejamento urbano no Brasil. In ARANTES, Otília, VAINER, Carlos; MARICATO, Ermínia (Org.). A cidade do pensamento único: desmanchando consensos. Petrópolis: Vozes, 2000, p. 121-192.

MINISTÉRIO DA CULTURA. Cultura é um bom negócio. Brasília: MINC, 1995.

MINISTÉRIO DA CULTURA. Cultura Viva. Brasília: MINC. Disponível em http://www. cultura.gov.br/cultura-viva1. Acesso em 10/6/2018.

MINISTÉRIO DA CULTURA. Pontos de Cultura. Brasília: MINC. Disponível em http://www.cultura.gov.br/culturaviva/ponto-de-cultura/. Acesso em 10/6/2018.

MONTEIRO, Simone R. da R. Pires. O marco conceitual da vulnerabilidade social. Sociedade em Debate, Pelotas, v. 17, n. 2, p. 29-40, jul.-dez. 2011.

MUSEUSBR - Rede Nacional De Identificação De Museus. Base de dados. Disponível em http://museus.cultura.gov.br. Acesso em 10/3/2018.

PAULA, Luciane de; PAULA, Sandra Leila de. No centro da periferia, a periferia no centro. Ipotesi: revista de estudos literários. v. 15, n. 2, p. 107-12, jul.-dez. 2011. Disponível em http://www.ufjf.br/revistaipotesi/files/2011/05/13-No-centro.pdf. Acesso em 24/5/2018.

PREFEITURA DA CIDADE DO RIO DE JANEIRO. Bairros Cariocas. Armazém de dados. Disponível em http://portalgeo.rio.rj.gov.br/bairroscariocas/index_bairro.htm. Acesso em $7 / 3 / 2018$.

RUBIM, Antonio Albino Canelas. Políticas culturais no Brasil: tristes tradições, enormes desafios. In RUBIM, A. A. C.; BARBALHO, A. (Org.) Políticas culturais no Brasil. Coleção Cult. Salvador: EDUFBA, 2007, p. 11-36. 


\section{Notas}

${ }^{1}$ O presente artigo é parte do desenvolvimento da pesquisa de mestrado "Tão perto e tão distante: arte, mediação e o significado de práticas culturais para as classes populares do Centro do Rio de Janeiro", vinculada ao Programa de Pós-Graduação em Estudos Contemporâneos das Artes (UFF), na linha de Estudos das Artes em Contextos Sociais, sob orientação da Professora Doutora Lígia Dabul.

${ }^{2}$ Ver, por exemplo, trabalhos como os de Frederico (2013) - que aborda as relações entre cultura e política a partir do que chama de explosão cultural da periferia - e Paula \& Paula (2011) - sobre o funk carioca através da reflexão sobre cronotopia utilizada por Mikhail Bakhtin.

${ }^{3}$ Museu do Amanhã, Museu de Arte do Rio, Museu Nacional de Belas Artes, Museu Histórico Nacional, Museu de Arte Moderna, Casa França-Brasil, Centro Cultural Paço Imperial, Conjunto Cultural da Caixa, Centro Cultural da Justiça Federal, Centro Cultural dos Correios, Centro Cultural Banco do Brasil, Centro Municipal de Arte Hélio Oiticica, Theatro Municipal, Teatro SESI, Teatro SESC Ginástico, Teatro Dulcina, Teatro Nelson Rodrigues, Teatro Carlos Gomes, Teatro João Caetano, Teatro Glauce Rocha, Teatro Serrador, Teatro Riachuelo, Sala Cecília Meireles, Circo Voador, Fundição Progresso, Biblioteca Nacional, Real Gabinete Português de Leitura, Cinema Odeon, entre outros, são alguns exemplos de equipamentos culturais que podem ser encontrados na região.

${ }^{4}$ Segundo Monteiro (2011), a formulação do conceito de vulnerabilidade social ainda é amplamente debatida, principalmente na área de assistência social, visto que são múltiplos seus condicionantes. Aqui o termo é compreendido como a exposição dos indivíduos a riscos de diferentes naturezas (econômicos, culturais e/ou sociais), que os impedem de satisfazer necessidades básicas.

${ }^{5}$ Dados sobre a visitação de exposições de curta duração realizadas em todo o território nacional passaram a ser coletados, gerenciados, tratados e compartilhados desde 2010 através do projeto Exposições no Brasil, do Instituto Brasileiro de Museus, criado pelo presidente da República Luiz Inácio Lula da Silva em janeiro de 2009. Desta forma, foi possível registrar o aumento expressivo da visitação aos museus brasileiros. Em 2011, o CCBB RJ ocupa as $1^{\mathrm{a}}, 7^{\mathrm{a}}$ e $9^{\mathrm{a}}$ posições no ranking das vinte exposições mais visitadas do ano. Em 2012, a instituição ocupa as $2^{\mathrm{a}}$, $7^{\mathrm{a}}$ e $11^{\mathrm{a}}$ posições. Em 2013, $3^{\mathrm{a}}, 6^{\mathrm{a}}, 10^{\mathrm{a}}$ e $11^{\mathrm{a}}$; em 2014, $4^{\mathrm{a}}, 5^{\mathrm{a}}, 7^{\mathrm{a}}, 10^{\mathrm{a}}$ e $14^{\mathrm{a}}$; em $2015,10^{\mathrm{a}}$ e $12^{\mathrm{a}}$; e, em 2016, $1^{\mathrm{a}}, 2^{\mathrm{a}}$ e $3^{a}$ posições.

${ }^{6}$ Embora mantido financeiramente por uma instituição católica e por doações, o Pequenas Vozes do Carmelo não é um projeto religioso.

${ }^{7}$ Valor do salário mínimo em 2018: R\$ 954.

Poiésis, Niterói, v. 19, n. 31, jan./jun. 2018. 